\title{
Protective Immunity Induced in Mice by F8.1 and F8.2 Antigens Purified from Schistosoma mansoniEggs
}

\section{Claudia Campra Ferreira, Marcelo Matos Santoro, Alfredo Miranda Goes ${ }^{+}$}

\author{
Departamento de Bioquímica e Imunologia, Instituto de Ciências Biológicas, Universidade Federal de Minas \\ Gerais, Caixa Postal 486, 30161-970 Belo Horizonte, MG, Brasil
}

Schistosoma mansoni soluble egg antigens (SEA) were fractionated by isoelectric focusing, resulting in 20 components, characterized by $\mathrm{pH}$, absorbance and protein concentration. The higher absorbance fractions were submitted to electrophoresis, and fraction $8(F 8)$ presented a specific pattern of bands on its isoelectric point. Protein 3 was observed only on F8, and so, it was utilized to rabbit immunization, in order to evaluate its capacity of inducing protective immunity. IgG antibodies from rabbit anti-F8 serum were coupled to Sepharose, and used to obtain the specific antigen by affinity chromatography. This antigen, submitted to electrophoresis, presented two proteic bands (F8.1 and F8.2), which were transferred to nitrocellulose membrane (PVDF) and sequenciated. The homology of F8.2 to known proteins was determined using the Basic Local Alignment Search Tool program (BLASTp). Significant homologies were obtained for the rabbit cytosolic $\mathrm{Ca}^{2+}$ uptake inhibitor, and for the bird $\mathrm{a}_{1^{-}}$ proteinase inhibitor. Immunization of mice with F8.1 and F8.2, in the presence of Corynebacterium parvum and $\mathrm{Al}(\mathrm{OH})_{3}$ as adjuvant, induced a significant protection degree against challenge infection, as observed by the decrease on worm burden recovered from portal system.

Key words: Schistosoma mansoni - egg antigen purification - immunity - vaccine

Schistosoma mansoni infection is characterized by the presence of adult worms in the portal and mesenteric veins as result of a complex migratory cycle, initiated by cutaneous penetration of cercariae, transformed into schistosomula in the skin of an appropriate host (Boros 1989). In mice, the pathology of schistosomiasis is associated with the daily production of viable eggs by the intravascular worms. Many eggs do not reach external environment and cause an inflammatory response when trapped in liver sinusoids, leading to predominantly cell-mediated granuloma formation and ultimately to hepatic fibrosis (Phillips \& Lammie et al. 1986). Numerous efforts over the last decade have focused the elaboration of a reliable vaccine able to protect humans against natural infection by $S$. mansoni. It is essential to have available defined, purified parasite antigens, allowing a better understanding of its immunogenic and biological functions (Kambara \& Wilson 1990, Hirsch et al. 1997).

\footnotetext{
This investigation received financial assistance from Conselho Nacional de Pesquisa (CNPq/PIBIC), PróReitoria de Pesquisa da Universidade Federal de Minas Gerais (PRPq/UFMG) and Fundação de Amparo à Pesquisa de Minas Gerais (Fapemig/Probic).

${ }^{+}$Corresponding author. Fax: +55-31-441.5963. E-mail: goes@mono.icb.ufmg.br

Received 4 May 1998

Accepted 31 August 1998
}

Some antigens have been purified from parasite eggs, using either conventional purification techniques (Lukacs \& Boros 1992, Hirsch \& Goes 1996) or affinity chromatography with human monoclonal antibodies (Hirsch et al. 1997). It has been previously demonstrated that fractions of $S$. mansoni soluble egg antigens were able to sensitize and elicit granulomatous hypersensitivity in mice (Harn et al. 1989, Lukacs \& Boros 1991). In this study, we report the characterization of $S$. mansoni egg antigens fractionated by liquid isoelectric focusing and their capacity to induce protection against a challenge infection.

\section{MATERIALS AND METHODS}

Mice and parasites - Adult female BALB/c mice, purchased from Centro de Bioterismo, ICB, UFMG, Belo Horizonte, Brazil, and maintained under standard laboratory care, were used throughout this study. Cercariae of $S$. mansoni were obtained from Biomphalaria glabrata snails, previously infected with miracidia of the L.E. strain, from Belo Horizonte, Brazil. Anesthetized mice (10/group) were exposed to cercariae on the abdomen, using the ring method of Smithers and Terry (1965). Vaccinated and control mice challenged with cercariae were perfused eight weeks after exposure (Smithers \& Terry 1965). The protective immunity of each group was evaluated by comparing the recovery of worms from immunized and control mice. 
SEA fractionation - Soluble eggs anigen (SEA) was fractionated by isoelectric focusing (IEF) in a liquid cell (Rotofor Cell, BioRad, Richmond, CA) according to manufacture's instructions. Briefly, $5 \mathrm{mg}$ SEA were diluted tenfold with $3 \mathrm{M}$ urea including a final ampholyte (pH 3-10, Pharmacia, Piscataway, NJ) concentration of $4 \%$. SEA was applied and focused for approximately 500 volts for $3 \mathrm{hr}$. Subsequently, 20 fractions, designated F1 to $\mathrm{F} 20$, were harvested and the $\mathrm{pH}$ of each fraction was measured (Fig. 1). To remove ampholytes, fractions were dialysed against phosphate buffer saline (PBS). Protein concentration of each fraction was measured according to Bradford microassay (Bradford 1976).

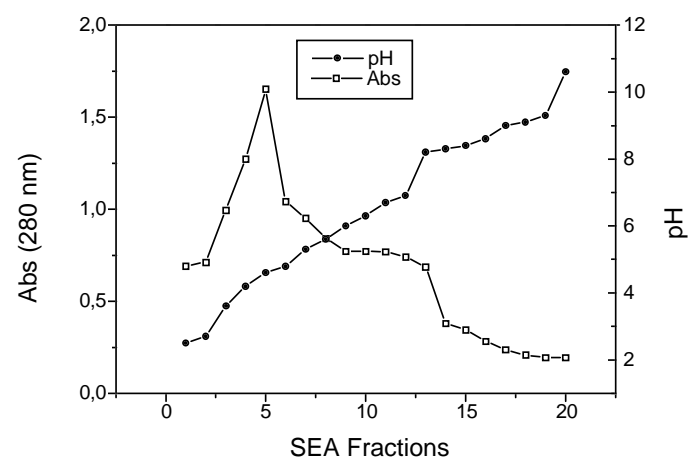

Fig. 1: elution profile of SEA by liquid isoelectric focusing in rotofor cell. $5 \mathrm{mg}$ of SEA were diluted tenfold with $3 \mathrm{M}$ urea including a final ampholyte ( $\mathrm{pH} 3-10)$ concentration of $4 \%$ at 500 volts for $3 \mathrm{hr}$. This procedure resulted in 20 fractions, characterized by $\mathrm{pH}$, absorbance and protein concentration.

SDS-polyacrylamide gel electrophoresis (SDS$P A G E)$ and Western blot - Isoeletric fractions separated by SDS-PAGE (Laemmli 1970) were either Coomassie blue stained or electrophoretically transferred to nitrocellulose membrane (BioRad), as described by Towbin et al. (1979).

Production of rabbit anti-serum to Protein 3 The protein 3 (M.W. of $68 \mathrm{kDa}$ ) of F8 fraction (pI 5.8) was excised from SDS-PAGE and used as immunogen. For immunization, Coomassie bluestained protein was cut of two to three gels, washed with PBS, and homogenized with $0.5 \mathrm{ml}$ of PBS. The antiserum was obtained from rabbits immunized by i.m. injections of sample emulsified with complete Freund adjuvant at a 1:1 ratio, and boosted twice at 2-week intervals with identical antigen amounts but in incomplete Freund adjuvant. Specific rabbit antibodies were coupled to cyanogen bromide-activated Sepharose-4B, and F8.1 and F8.2 proteins were purified as described by Goding (1986).
Amino-terminal sequencing - The SDS-PAGE Protein 3 was electrophoretically transferred to polyvinylidine difluoride membranes (PVDF, 0.2 $\mathrm{mm}$, BioRad) with the transblot apparatus, at a constant current of $50 \mathrm{~mA}$, overnight. Transfers were stained for 1 min with $1 \%$ Ponceau S in $10 \%$ acetic acid, briefly destained in distilled water, and air-dried. Protein was cut from membranes, and amino-terminal sequencing were performed by Centro Brasileiro de Sequenciamento de Proteínas, Universidade de Brasília, Brasília, DF, Brazil. To determine sequence homology, amino acid sequences were compared to protein sequences in non-redundant data bases, using the Basic Local Alignment Search Tool program (BLASTp) (Altschul et al. 1990), at National Center for Biotechnology Information (NCMI).

Immunization of mice with F8.1 and F8.2 Groups of five BALB/c mice were immunized by s.c. injections of $10 \mathrm{mg}$ of each F8.1 and F8.2 preparation, in presence of $100 \mathrm{mg}$ of Corynebacterium parvum and $1 \mathrm{mg}$ of aluminium hydroxide $\left[\mathrm{Al}(\mathrm{OH})_{3}\right]$ as adjuvant. Animals were boosted twice, at 2-week intervals, with identical amounts of antigen, but the last injection was done by i.p. without adjuvant.

\section{RESULTS}

Fractionation of SEA by IEF and purification of F8.1 and F8.2 by affinity chromatography - In the present study, utilizing two different procedures, we purified F8.1 and F8.2 from S. mansoni egg antigens. Results presented in Fig. 1 depict the fractionation of SEA utilizing liquid isoelectric focusing in a Rotofor Cell system. This procedure resulted in 20 fractions, characterized by $\mathrm{pH}$, absorbance and protein concentration. The higher absorbance fractions were submitted to electrophoresis, and fraction 8, denominated F8, pI 5.8, presented a specific pattern of bands on its isoeletric point. Protein 3 was observed only on F8, and so, was utilized to rabbit immunization.

Immunoaffinity chromatography was applied to purify Protein 3 from F8, prepared in the absence of protease inhibitors, using specific rabbit antibodies coupled to Sepharose-4B. The purified antigen, submitted to SDS-PAGE and Western blot analysis, revealed to have two proteic bands, denominated F8.1 and F8.2, with respectively M.W. of $70 \mathrm{kDa}$ and $68 \mathrm{kDa}$ (Fig. 2). The amino acid sequence data obtained for 20 amino-terminal residues of F8.2 protein are presented in Table. This partial amino acid sequencing indicated strong sequence homology to rabbit cytosolic $\mathrm{Ca}^{2+}$ uptake inhibitor antagonist and to a 1 - proteinase inhibitor $(100 \%$ homology). 
Immunization of mice with F8.1 and F8.2, and their effect on a subsequent infection with $S$. mansoni cercariae - The protective effect of immunization with F8.1 and F8.2, in the presence of C. parvum and $\mathrm{Al}(\mathrm{OH})_{3}$ as adjuvant, was additionally investigated in mice. As shown in Fig. 3,

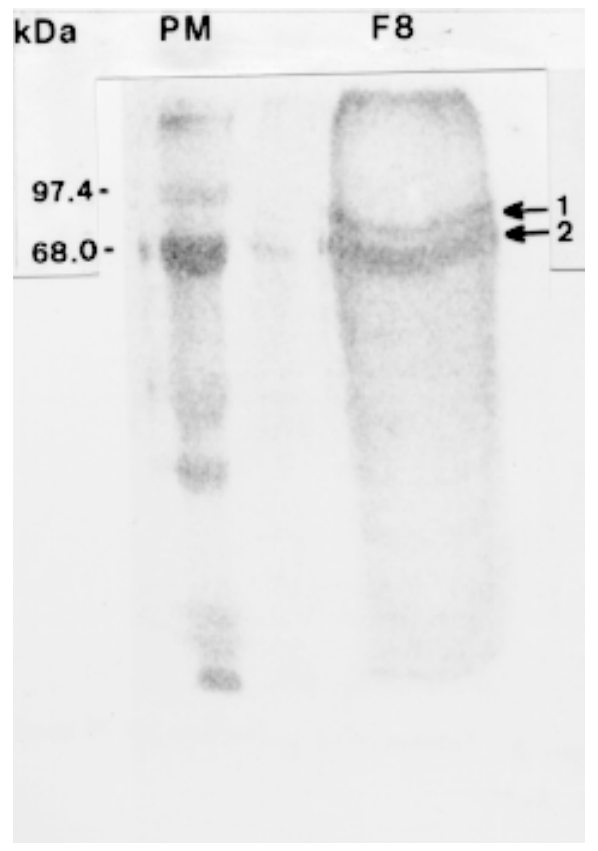

Fig. 2: SDS-PAGE of Schistosoma mansoni egg antigen affinity purified Protein 3 . Samples (F8) and molecular weight marker (PM) were applied to $10 \%$ SDS-PAGE under reducing conditions, followed by Coomassie blue stain. Two separated proteins were evidenciated: F8.1 and F8.2. the number of worms, recovered eight weeks after challenge infection of immunized animals, was significantly reduced when compared to that observed on adjuvant-immunized or not-immunized control mice. Immunization with F8.1 and F8.2 established a protection of $29 \%$ and $35 \%$, respectively.

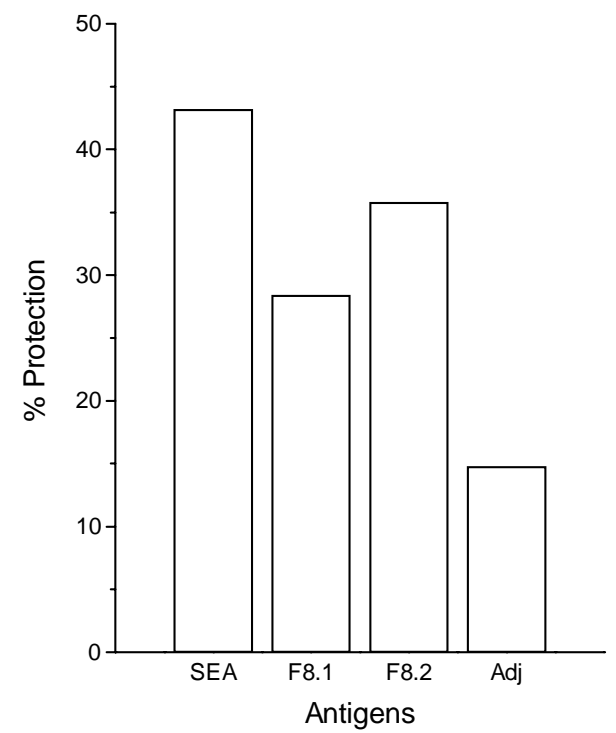

Fig. 3: protective effect of F8.1 and F8.2. BALB/c mice were immunized with $10 \mathrm{mg}$ of each antigen, in presence of Corynebacterium parvum and $\mathrm{Al}(\mathrm{OH})_{3}$, as described on Materials and Methods. Worm burden was determined by perfusion of portal system, at eight weeks after challenge infection, in five mice/ group. $\%$ protection $=100-$ experimental/control x 100 .

TABLE

Protein sequence homology between F8.2 of Schistosoma mansoni and other species

\begin{tabular}{|c|c|c|c|c|c|c|}
\hline Homology ${ }^{a}$ & Animals & $\begin{array}{l}\text { Similarity } \\
(\%)\end{array}$ & $\begin{array}{c}\text { Identity } \\
(\%)\end{array}$ & $\begin{array}{l}\text { Size } \\
\text { (aa) }\end{array}$ & Score & Probability \\
\hline $\begin{array}{l}\text { Antagonist protein, cytosolic } \mathrm{Ca}^{2+} \text { uptake } \\
\text { inhibitor antagonist/serum albumin homolog }\end{array}$ & rabbits & 100 & 100 & 13 & 69 & 0.00014 \\
\hline$a_{1}$-proteinase inhibitor & birds & 100 & 83 & 12 & 59 & 0.0043 \\
\hline $\begin{array}{l}70 \mathrm{kDa} \text { seizure activity-linked albumin-like } \\
\text { glycoprotein }\end{array}$ & rats & 92 & 84 & 13 & 60 & 0.0047 \\
\hline TB66 $=66 \mathrm{kda}$ seroreactive protein & $\begin{array}{l}\text { Mycobacterium } \\
\text { tuberculosis }\end{array}$ & 92 & 83 & 14 & 56 & 0.017 \\
\hline Serum albumin (fragment) & human & 92 & 76 & 13 & 59 & 0.0054 \\
\hline $49 \mathrm{kDa}$ protein (cornea peptide) & rats & 92 & 76 & 13 & 59 & 0.0062 \\
\hline
\end{tabular}

a: N-Terminal sequence of F8.2: E A H K S E I A H R F N D V Q X E H F I G L V L

This protein was compared to protein sequences deposited in non-redundant databases, using the Basic Local Alignment Search Tool program, BLASTp. 


\section{DISCUSSION}

In this study we identified immunogenic components of $S$. mansoni egg antigen preparation essential to the formulation of a schistosomiasis vaccine. In order to conduct this issue we used two approaches to obtain purified antigens: isoelectric focusing and affinity chromatography.

The technique of liquid isoelectric focusing has many features which make it a valuable tool in our search for antigens involved in the expression of protective immunity to schistosomes (Mountford $\&$ Wilson 1993). It permits fractionation of relatively small quantities of soluble protein mixtures, with a recovery rate greater than $90 \%$. The system has the capacity to fractionate complex antigen preparations such as SEA, which encompass a wide range of protein sizes into 20 samples, each one containing a slightly different range of proteins. The eluted proteins are in aqueous form, in small volume, and at a relatively high concentration. In this system, we were able to identify Protein 3 only on fraction 8 , and so, it was utilized to rabbit immunization.

Another procedure utilized for purification of Protein 3 involved affinity chromatography using rabbit anti-Protein $3 \mathrm{IgG}$ coupled to Sepharose. The analysis of SDS-PAGE purified antigen showed that Protein 3 was constituted by two antigens, F8.1 and F8.2, with respectively M.W. of $70 \mathrm{kDa}$ and $68 \mathrm{kDa}$. Amino acid sequence data obtained for the 20 amino-terminal residues of F8.2 protein showed a $100 \%$ homology with a rabbit antagonist protein, cytosolic $\mathrm{Ca}^{2+}$ uptake inhibitor antagonist (Xu \& Narayanan 1994), and with $\mathrm{a}_{1}$-proteinase inhibitor (Kuhn et al. 1994).

The role of F8.1 and F8.2 as protective antigens was supported by mice immunization. Three successive immunizations, in the presence of C. parvum and $\mathrm{Al}(\mathrm{OH})_{3}$, gave a significant level of resistance to subsequent cercarial challenge. Several groups have demonstrated the potential vaccinating effect of different $S$. mansoni antigens and obtained various levels of protection. Smith and Clegg (1985) vaccinated mice with two schistosome surface antigens of 155 and $53 \mathrm{kDa}$, and obtained a level of protection around 30\%. Other groups have identified potential antigens for vaccination using indirect methods, particularly by production of monoclonal antibodies associated with protective activity in passive transfer experiments (Smith et al. 1982, Harn et al. 1984, Hirsch et al. 1997). Sher et al. (1986) identified a $97 \mathrm{kDa}$ immunogen relevant to the induction of protection in mice. Recently, other vaccine candidates were described: a $22.6 \mathrm{kDa}$ membrane-associated antigen (Jeffs et al. 1991), and 44.7/56.8 kDa egg an- tigens recognized by human monoclonal antibodies (Hirsch et al. 1997).

Data presented here clearly demonstrate that F8.1 and F8.2 might be of help in the formulation of a vaccine, which could reduce worm burden.

\section{REFERENCES}

Altschul SF, Gish W, Miller W, Myers EW, Lipman DJ 1990. Basic local alignment search tool. J Mol Biol 215: 403-410.

Boros DL 1989. Immunopathology of Schistosoma mansoni infection. Clin Microbiol Rev 2: 250-269.

Bradford MM 1976. A rapid and sensitive method for the quantification of microgram quantities of protein utilizing the principle of protein-dye binding. Anal Bioch 72: 248-254.

Goding JW 1986. Monoclonal Antibodies: Principles and Practice, 2nd ed., Academic Press, London, 315 pp.

Harn DA, Mitsuyama M, David JR 1984. Schistosoma mansoni: anti-egg monoclonal antibodies protect against cercarial challenge in vivo. J Exp Med 159: 1371-1387.

Harn DA, Danko K, Quinn JJ, Stadecker MJ 1989. Schistosoma mansoni: the host immune response egg antigens. I. Partial characterization of cellular and humoral responses to $\mathrm{pI}$ fractions of soluble egg antigens. J Immunol 142: 2061-2066.

Hirsch C, Goes AM 1996. Characterization of fractioned Schistosoma mansoni soluble adult worm antigens that elicit human cell proliferation and granuloma in vitro. Parasitology 112: 529-535.

Hirsch C, Zouain CS, Alves JB, Goes AM 1997. Induction of protective immunity and modulation of granulomatous hypersensitivity in mice using PIII an anionic fraction of Schistosoma mansoni adult worm. Parasitology 115: 21-28.

Jeffs SA, Hagan P, Allen R, Correa-Oliveira R, Smithers R, Simpson A 1991. Molecular cloning and characterization of the 22-kilodalton adult Schistosoma mansoni antigen recognized by antibodies from mice protectively vaccinated with isolated tegumental surface membranes. Mol Biochem Parasitol 46: 159-168.

Kambara T, Wilson RA 1990. In situ pulmonary responses of $\mathrm{T}$ cell and macrophage subpopulations to a challenge infection im mice vaccinated with irradiated cercariae of Schistosoma mansoni. J Parasitol 76: 365-372.

Kuhn CR, Naude RJ, Travis J, Oelofsen W 1994. The isolation and partial characterization of alpha 1-proteinase inhibitor from the serum of the ostrich (Struthio camelus). Int J Biochem 26: 843-853.

Laemmli UK 1970. Cleavage of structural proteins during the assembly of the head of the bacteriophage T4. Nature 227: 680-685.

Lukacs NW, Boros DL 1991. Splenic and granuloma Tlymphocyte responses to fractionated soluble egg antigens of Schistosoma mansoni infected mice. Infect Immun 59: 941-948.

Lukacs NW, Boros DL 1992. Utilization of fractionated soluble egg antigens reveals selectively modulated granulomatous and lymphokine responses during murine schistosomiasis mansoni. Infect Immun 60: 3209-3216. 
Mountford AP, Wilson RA 1993. Fractionation of schistosome antigens by high performance electrophoretic chromatography and their screening for the ability to induce Th1 lymphocyte activity. J Immunol Meth 160: 237-244.

Philips SM, Lammie PJ 1986. Immunopathology of granuloma formation and fibrosis in schitosomiasis. Parasitol Today 2: 296-302.

Sher A, Pearce E, Hieny S, James S 1986. Indution of protective immunity against Schistosoma mansoni by a non-living vaccine. IV. Fractionation and antigenic properties of a soluble adult worm; immunoprophylactic activity. J Immunol 136: 38783884.

Smith MA, Clegg JA 1985. Vaccination against Schistosoma mansoni with purified surface antigens. Science 277: 535-538.
Smith MA, Clegg JA, Snary D, Trejdosiewicz AJ 1982. Passive immunization of mice against Schistosoma mansoni with an IgM monoclonal antibody. Parasitol 84: 83-91.

Smithers SR, Terry RJ 1965. The infection of laboratory hosts with cercariae of Schistosoma mansoni and the recovery of adult worms. Parasitology 55: 565-570.

Towbin H, Stachelin T, Gordon J 1979. Eletrophoretic transfer of proteins from polyacrilamyde gels to nitrocellulose sheets: procedure and some applications. Proc Natl Acad Sci USA 76: 4350-4354.

Xu A, Narayanan N 1994. Purification amino-terminal sequence and functional properties of a $64 \mathrm{kDa}$ cytosolic protein from heart muscle capable of modulating calcium transport across the sarcoplasmic reticulum in vitro. Mol Cell Biochem 132: 7-14. 
Antigens Purified from S. mansoni - Claudia C Ferreira et al. 